\title{
Nursing Information System
}

National Cancer Institute

\section{Source}

National Cancer Institute. Nursing Information System. NCI Thesaurus. Code C19379.

Computer systems designed to assist in the management and processing of nursing data including decision support systems to support the practice of nursing and the delivery of nursing care. 